\title{
Salivary cortisol in the diagnosis of adrenal insufficiency: cost efficient and patient friendly
}

\author{
Marloes L P Langelaan ${ }^{1,2}$, Jérôme M H Kisters ${ }^{3}$, Mirjam M Oosterwerff ${ }^{3}$ and Arjen-Kars Boer ${ }^{1}$ \\ ${ }^{1}$ Clinical Laboratory, Catharina Hospital Eindhoven, Eindhoven, The Netherlands \\ ${ }^{2}$ Department of Clinical Chemistry and Haematology, Zuyderland Medical Centre, Heerlen, The Netherlands \\ ${ }^{3}$ Department of Internal Medicine, Catharina Hospital Eindhoven, Eindhoven, The Netherlands \\ Correspondence should be addressed to A-K Boer: arjen-kars.boer@catharinaziekenhuis.nl
}

\begin{abstract}
Saliva as a diagnostic tool is patient friendly and offers analytical advantages. Hormonal analysis of saliva is not influenced by changes in concentrations of binding globulins as the free concentration of the hormones is measured. Analysis of salivary cortisol is common practice in the diagnostic work-up of hypercortisolism. We investigated the potential role of measuring salivary cortisol when adrenal insufficiency (AI) is suspected, to reduce the numbers of ACTH stimulation tests. Over a period of 6 years, patients undergoing an ACTH stimulation test (tetracosactide, $250 \mu \mathrm{g}$ ) in our hospital were included. Plasma cortisol (Elecsys, Cobas, Roche Diagnostics) and salivary cortisol and cortisone (LC-MS/MS) were determined at $t=0,30$ and 60 min after stimulation. Based on peak plasma cortisol levels, Al was ruled out in 113 patients and was established in 16 patients. Patients without Al displayed maximal salivary cortisol concentrations of $12.6-123.4 \mathrm{nmol} / \mathrm{L}$ (95th percentile) after stimulation, as opposed to $0.5-15.2 \mathrm{nmol} / \mathrm{L}$ in Al patients. At $t=0 \mathrm{~min}$, a minimal salivary cortisol concentration of $1.0 \mathrm{nmol} / \mathrm{L}$ was observed in patients without Al, whereas Al patients had a maximum concentration of $5.9 \mathrm{nmol} / \mathrm{L}$. Using these cut-off values, $34 \%$ of the initial patient group could be diagnosed without an ACTH stimulation test $(28 \%>5.9 \mathrm{nmol} / \mathrm{L}, 6 \%<1.0 \mathrm{nmol} / \mathrm{L})$. A novel diagnostic algorithm, including early morning salivary cortisol analysis can reduce the numbers of ACTH stimulation tests in patients suspected of Al. This patient-friendly method can thereby reduce total health care costs.
\end{abstract}

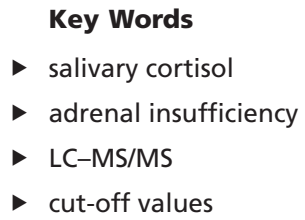

Endocrine Connections (2018) 7, 560-566

\section{Introduction}

The utility of measuring salivary cortisol has become increasingly popular in, for example, screening for Cushing's syndrome or disease $(1,2)$. Obtaining salivary samples is easy and patient friendly. An additional advantage is that salivary cortisol is in equilibrium with plasma-free cortisol and therefore a surrogate for the concentration of plasma-free cortisol. As opposed to total plasma cortisol, salivary cortisol is thus independent of changes in concentrations of binding proteins, such as CBG and albumin.

An emerging role for salivary cortisol in the diagnosis of adrenal insufficiency (AI) has, however, still to be

$$
\begin{array}{lr}
\text { http://www.endocrineconnections.org } & \text { ๑ } 2018 \text { The authors } \\
\text { https://doi.org/10.1530/EC-18-0085 } & \text { Published by Bioscientifica Ltd }
\end{array}
$$

defined. We investigated whether early morning salivary cortisol can be used to prevent ACTH stimulation tests in patients suspected of AI.

As recommended in the recent practical guideline of the Endocrine Society, diagnostic testing for primary AI should include a short $250 \mu \mathrm{g}$ ACTH stimulation test (3). If not available, initial screening should comprise a morning plasma ACTH and (total) cortisol. Common medical practice in the Netherlands, however, requires admittance to hospital and careful guidance by medical personnel during an ACTH stimulation test $(3,4)$. Preventing unnecessary ACTH stimulation tests could 
thus be beneficial for patient welfare as well as reduction of costs. Additionally, potential adverse drug reactions to tetracosactide, ranging from skin irritation to an anaphylactic shock, could be prevented (5).

Until now, the use of subnormal concentrations of early morning salivary cortisol in the diagnostic work-up of AI has suffered from some analytical drawbacks. Restituto et al. (2008) reported a low sensitivity and specificity (33\% and $20 \%$ respectively) based on cut-off values determined by the optimal Youden index (6). More recent research, however, using an electrochemiluminescence immunoassay, reported a $\geq 95 \%$ specificity, but $40 \%$ sensitivity (7). Others concluded that the wide range of salivary cortisol concentrations in healthy individuals would hamper the identification of AI (1).

However, novel liquid chromatography tandemmass spectrometry (LC-MS/MS) techniques have made it possible to increase accuracy and sensitivity in the determination of salivary cortisol concentrations (8, 9). LC-MS/MS analyses are not influenced by changes in e.g. concentrations of cortisol-binding globulin or cross-reactivity with other corticosteroid substances. In addition, LC-MS/MS analysis enables the analysis of cortisol and cortisone in one run. Possible interference of 11 $\beta$-hydroxysteroid dehydrogenase-modulating agents can thus be evaluated.

We investigated whether early morning salivary cortisol determined by LC-MS/MS could be used in the diagnosis of AI. In our study, AI patients were diagnosed by an ACTH stimulation test and subsequent evaluation of peak plasma cortisol levels. We defined reference values for salivary cortisol and cortisone during these ACTH stimulation tests and determined cut-off values that could be used to diagnose or rule out AI. These cut-off values were used to investigate their impact on preventing ACTH stimulation tests in the diagnostic work-up of AI.

\section{Materials and methods}

\section{Patients}

The study group consisted of patients with a clinical suspicion of AI that underwent an ACTH stimulation test in our hospital between July 2010 and May 2016. Clinical suspicion was based on a subnormal morning plasma cortisol concentration or one of the following signs and symptoms: orthostatic hypotension, abdominal pain, salt craving. In total, 129 patients were included (47 male, 82 female; mean age 48 years). AI was ruled out when peak

$$
\text { http://www.endocrineconnections.org }
$$

cortisol concentrations were above assay-specific cut-off values (see 'Plasma cortisol' section) during the ACTH stimulation test $(3,4)$. In retrospect, the group consisted of 113 patients in whom AI was ruled out (36 male, 77 female; mean age 46 years) and 16 AI patients (11 male, 5 female; mean age 56 years).

Our study did not require approval of a local ethical committee or consent of subjects as it only concerned retrospective data analysis. Salivary cortisol analysis was considered standard care in our hospital, upon introduction of the analysis method and was included in protocols for the ACTH stimulation test.

\section{ACTH stimulation test}

Patients undergoing an ACTH stimulation test underwent day case admission to our hospital, starting early morning (08:00h). Directly after admission, plasma (lithium heparin, BD Vacutainer, Becton Dickinson, Breda, the Netherlands) and salivary (Salivette, Sarstedt, Etten-Leur, the Netherlands) samples were collected to define baseline values of plasma cortisol as well as salivary cortisol and cortisone $(t=0 \mathrm{~min})$. Next, $250 \mu \mathrm{g}$ of tetracosactide (Synacthen) was injected intravenously. At $t=30$ and 60 min after injection, plasma cortisol as well as salivary cortisol and cortisone concentrations were determined.

\section{Cortisol and cortisone measurements}

\section{Plasma cortisol}

Plasma cortisol concentrations were determined in heparin plasma by an automated immunochemiluminescence assay (Elecsys, Cobas, Roche Diagnostics). Patients enrolled in our study until November 2015 were measured by the cortisol I assay, whereas patients enrolled from November 2015 onwards were measured by the cortisol II assay.

\section{Salivary cortisol and cortisone}

Salivary samples were collected by chewing a cylindrical synthetic swab (Salivette, Sarstedt) for approximately $1 \mathrm{~min}$. The patients were told not to eat or brush their teeth in a period of $30 \mathrm{~min}$ before collection. Samples were centrifuged at $2682 \boldsymbol{g}$ for $10 \mathrm{~min}$, after which the synthetic swab was removed and collected saliva was stored at $-20^{\circ} \mathrm{C}$ until further analysis.

Deuterated internal standards for cortisol (cortisol-d4, Sigma-Aldrich, ref. 705594) and cortisone (cortisone-d7, Sigma-Aldrich, ref. 705586) were added to the samples, followed by liquid-liquid extraction using tert-butyl 
methyl ether (MS-grade), evaporation under nitrogen and reconstitution in a 50\% methanol (MS-grade)/water solution. Two microliters of reconstituted sample were injected in a UPLC system (Xevo TQ-S, Waters, Milford, SA, USA) and separated using a ACQUITY HSS T3 column $(50 \times 2.1 \mathrm{~mm}, 1.8 \mu \mathrm{m}$, Waters $)$ with a 4 -min gradient of aqueous ammonium acetate ( $2 \mathrm{mM}$ (MS-grade) in $0.1 \%$ formic acid and methanol (MS-grade), $0.4 \mathrm{~mL} / \mathrm{min}$ ). Detection and quantification were performed by a tandem quadrupole mass spectrometer (Xevo TQ-S, Waters Chromatography) equipped with a heated electrospray ionization source, operating in positive ion mode. Ionization parameters were spray voltage $1.0 \mathrm{kV}$, desolvation temperature $500^{\circ} \mathrm{C}$, source temperature $150^{\circ} \mathrm{C}$, nitrogen cone (flow $150 \mathrm{~L} / \mathrm{h}$ ) and desolvation (flow $1000 \mathrm{~L} / \mathrm{h}$ ) gas. The extractor was set at $3.00 \mathrm{kV}$. Collision-induced dissociation was performed using $\mathrm{Ar}$ as the collision gas at a flow of $0.1 \mathrm{~mL} / \mathrm{min}$. Quantification was based on selective reaction monitoring following the transitions $\mathrm{m} / \mathrm{z} \quad 363.2 \rightarrow 121.1$ (cone $38 \mathrm{~V}, \mathrm{CE}$ $32 \mathrm{eV}$ ) and $\mathrm{m} / \mathrm{z} 367.1 \rightarrow 121.1$ (cone $40 \mathrm{~V}, \mathrm{CE} 18 \mathrm{eV}$ ) for cortisol and cortisol-d4 respectively. Quantification of cortisone and cortisone-d7 was based on the transitions $\mathrm{m} / \mathrm{z} \quad 361.2 \rightarrow 163.1 \quad$ (cone $38 \mathrm{~V}, \quad \mathrm{CE} \quad 26 \mathrm{eV}$ ) and $\mathrm{m} / \mathrm{z} 369.1 \rightarrow 168.9$ (cone $52 \mathrm{~V}$, CE $28 \mathrm{eV}$ ) respectively. For both cortisol and cortisone, a qualifier ion was analyzed with transitions $\mathrm{m} / \mathrm{z} 363.2 \rightarrow 97.0$ (cone $38 \mathrm{~V}, \mathrm{CE} 46 \mathrm{eV}$ ) and $m / z 361.2 \rightarrow 163.1$ (cone $38 \mathrm{~V}, \mathrm{CE} 46 \mathrm{eV}$ ), respectively. Quantification was performed with an internal standard calculation method using 4 standards from 0.5 to $150 \mathrm{nmol} / \mathrm{L}$ for cortisol and 1.50 to $450 \mathrm{nmol} / \mathrm{L}$ for cortisone.

\section{Data analysis}

In this study, AI was ruled out when peak levels of plasma cortisol during the ACTH stimulation test were above $550 \mathrm{nmol} / \mathrm{L}$ for the cortisol I assay and above $420 \mathrm{nmol} / \mathrm{L}$ for the cortisol II assay $(3,10)$. The $420 \mathrm{nmol} / \mathrm{L}$ cut-off value for the cortisol II assay was based on the lower reference limit at $30 \mathrm{~min}$ after stimulation with ACTH, defined by the GC-MS reference method to which the cortisol II assay was standardized (10).

Concentrations of plasma cortisol as well as salivary cortisol and cortisone at $t=0,30$, and 60 min of the ACTH stimulation test were subjected to log-transformation because of skewed distribution. Reference values for salivary cortisol and cortisone were defined as 2.5th and 97.5th percentiles.

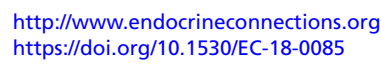

Cut-off values were generated for salivary cortisol and cortisone at $t=0$, defined as the minimum concentration observed in patients without AI and maximum concentration in AI patients. The newly defined cut-off values were used to evaluate the necessity of an ACTH stimulation test in the entire patient group.

\section{Results}

\section{Salivary cortisol and cortisone}

In patients without AI, reference values for salivary cortisol and cortisone were $1.6-34.4 \mathrm{nmol} / \mathrm{L}$ and $10.0-61.5 \mathrm{nmol} / \mathrm{L}$ respectively ( $t=0 \mathrm{~min}$, Fig. $1 \mathrm{~A}$ and B). As a consequence of stimulation by tetracosactide, these reference values rose to $9.0-68.1 \mathrm{nmol} / \mathrm{L}$ and $27.1-120.8 \mathrm{nmol} / \mathrm{L}$ for cortisol and cortisone respectively at $t=30 \mathrm{~min}$, and $12.6-123.4 \mathrm{nmol} / \mathrm{L}$ and $37.0-153.5 \mathrm{nmol} / \mathrm{L}$ at $t=60 \mathrm{~min}$. Minimum cortisol concentrations observed in patients without AI were 1.0, 3.2 , and $9.5 \mathrm{nmol} / \mathrm{L}$ at $t=0,30$ and $60 \mathrm{~min}$. Corresponding cortisone concentrations were 1.7, 19.1 and $30.0 \mathrm{nmol} / \mathrm{L}$.

In $\mathrm{AI}$ patients, maximum cortisol concentrations were $5.9,17.2$ and $15.6 \mathrm{nmol} / \mathrm{L}$ at $t=0,30$, and $60 \mathrm{~min}$. Corresponding cortisone concentrations were 33.8, 39.7 and $46.7 \mathrm{nmol} / \mathrm{L}$.

The lowest concentration of salivary cortisol observed at $t=0 \mathrm{~min}$ in patients without $\mathrm{AI}$ was $1.0 \mathrm{nmol} / \mathrm{L}$. On the contrary, the highest concentration of salivary cortisol at $t=0 \mathrm{~min}$ observed in AI patients was $5.9 \mathrm{nmol} / \mathrm{L}$. We defined these concentrations as cut-off values that were further investigated for potential usage in the diagnostic work-up of AI.

\section{Preventing ACTH stimulation tests by salivary cortisol and cortisone measurements}

By using the newly defined cut-off values for salivary cortisol (Fig. 1), we investigated their potential role in reducing the numbers of ACTH stimulation tests in the entire patient group (Fig. 2). We also investigated the effect of performing a second measurement of morning plasma cortisol, by considering the $t=0 \mathrm{~min}$ plasma cortisol as a second measurement in the patients (i.e. patients were enrolled in our study based on, among others, a previously measured subnormal morning plasma cortisol measurement).

Concentrations for plasma cortisol and salivary cortisol and cortisone at $t=0 \mathrm{~min}$ were used for the analysis, representing early morning values. Based on these plasma 
A
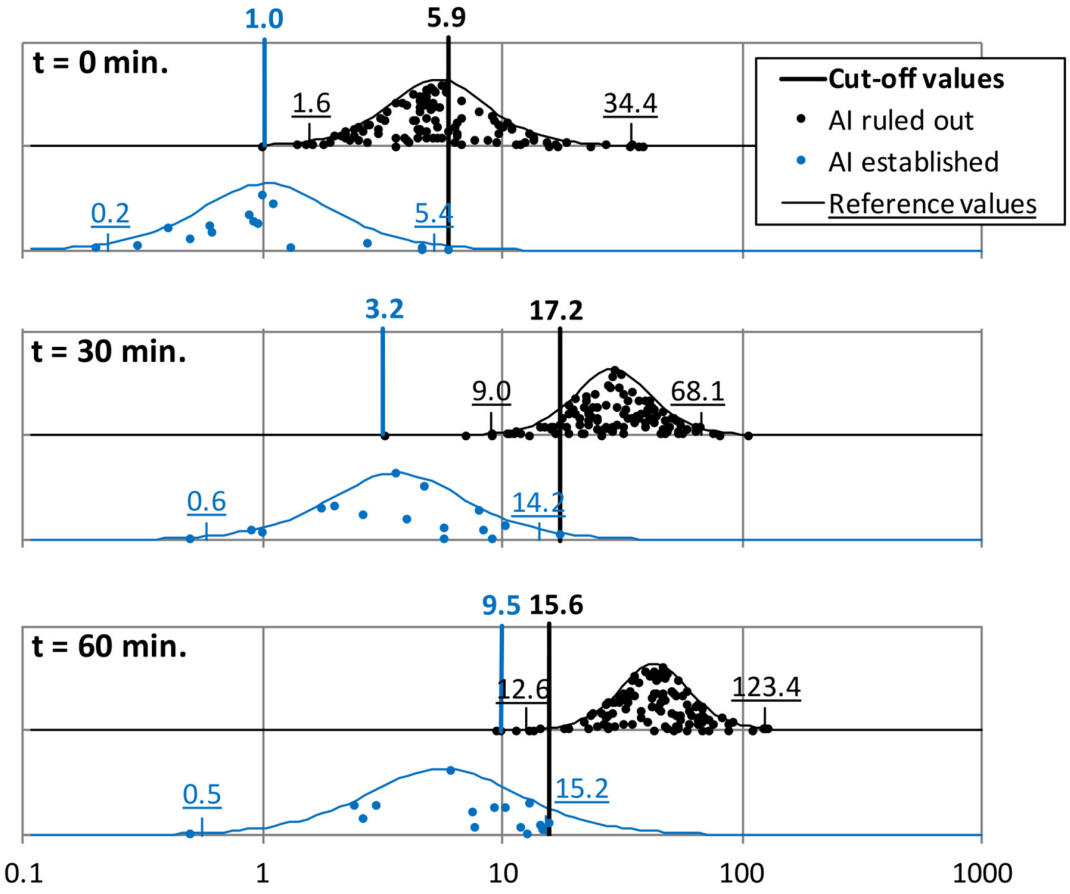

Salivary cortisol [nmol/L]

B
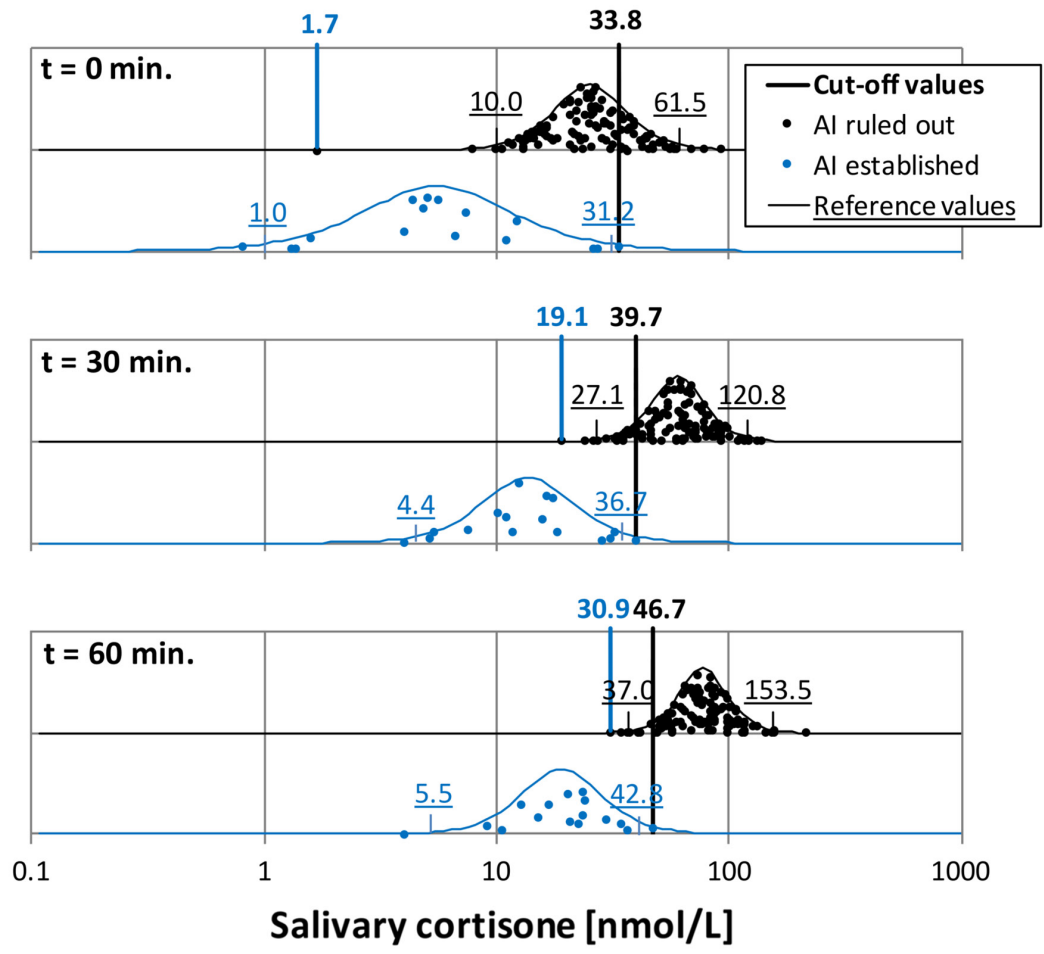

\section{Figure 1}

Salivary cortisol (A) and cortisone (B) concentrations during ACTH stimulation tests. Results are given for patients in whom Al was ruled out (black dots) or established (blue dots). Concentrations are shown on a logarithmic scale ( $X$-axis), accompanied by fitted normal distributions (black and blue lines) on an arbitrary $Y$-axis. Cut-off values (black and blue vertical lines, numbers in boldface) and reference values (underlined numbers in black and blue) are shown. cortisol concentrations, $9 \%$ of the patients had a normal plasma cortisol concentration (Fig. 2B). When the cutoff values for early morning salivary cortisol were used, this percentage increased to a remarkable 28\% (Fig. 2C) (for salivary cortisone this percentage was $26 \%$, data not shown).

http://www.endocrineconnections.org https://doi.org/10.1530/EC-18-0085

() 2018 The authors Published by Bioscientifica Ltd
Patients with a plasma (or salivary) cortisol below the cut-off of normal would still undergo an ACTH stimulation test, according to the recent guideline (3). We determined that the positive predictive value of plasma cortisol below $80 \mathrm{nmol} / \mathrm{L}$ and/or salivary cortisol below $1 \mathrm{nmol} / \mathrm{L}$ for the diagnosis of AI was $100 \%$. When

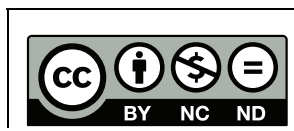

This work is licensed under a Creative Commons Attribution-NonCommercial-NoDerivatives 4.0 International License. 


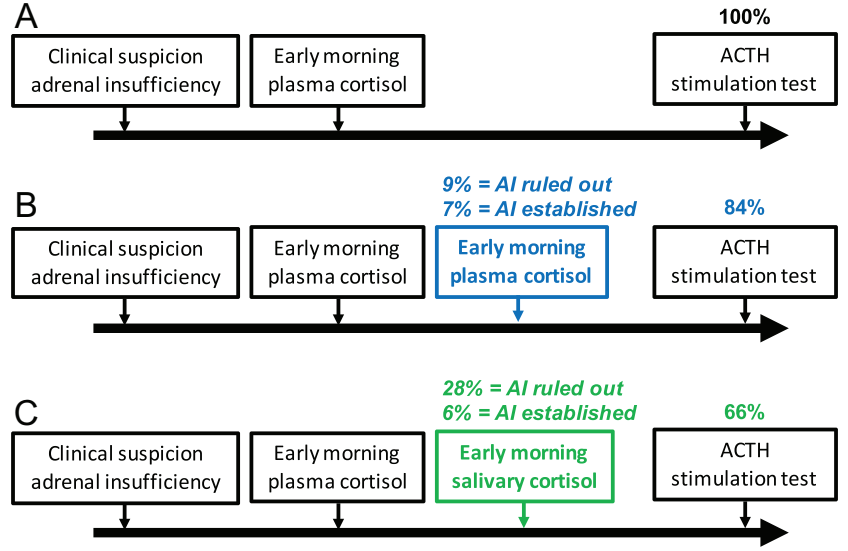

Figure 2

Effect of different diagnostic approaches on numbers of ACTH stimulation tests in patients suspected of adrenal insufficiency. Current protocols are considered the reference (A). An approach with a second plasma cortisol measurement, in addition to the plasma cortisol requested by the referring physician, is shown in panel B. Panel C displays an approach including salivary cortisol measurements. Percentages of patients with Al ruled out or established are given, as well as the percentage of ACTH stimulation tests performed using the different approaches in B and C.

these lower cut-off values were used in our study, 7\% of ACTH stimulation tests could be prevented based on a single plasma cortisol measurement, whereas $6 \%$ could be prevented based on a salivary cortisol measurement. Taken together, ACTH stimulation tests would be performed in $84 \%$ of the patients when a second plasma cortisol measurement is performed and only in 66\% of the patients when early morning salivary cortisol measurements are included in the diagnostic work-up (Fig. 2B and C).

\section{Discussion}

We demonstrated that measurements of salivary cortisol can play a role in the diagnostic approach of suspected AI. Based on our results, we propose a novel diagnostic flowchart that could be adopted in the work-up of AI by clinicians, after further validation in clinical studies (Fig. 3). Using this approach, we determined that the number of ACTH stimulation tests could be reduced by $28 \%$. An additional $6 \%$ of ACTH stimulation tests could be prevented if early morning cortisol levels below the minimum of normal are used to establish the diagnosis of AI. When early morning plasma cortisol was measured a second time in patients suspected of AI, only $9 \%$ appeared normal as opposed to the $28 \%$ based on salivary cortisol concentrations. These numbers highlight the power of measuring free cortisol concentrations in saliva. We postulate that serum free cortisol levels may be higher in these patients as well, as a result of reduced affinity with CBG and albumin $(11,12)$. However, serum or plasmafree cortisol measurements and measurements of CBG and albumin in these patients should be performed to underline this hypothesis.

Logically, adding salivary cortisol and cortisone analyses to the diagnostic work-up of suspected AI would increase laboratory costs. These costs are estimated as several hundreds of euros on an annual basis in our hospital (13). However, the 34\% reduction in ACTH stimulation tests that can be achieved by measuring salivary cortisol greatly counterbalances these analytical costs in the situation that day case admission to a hospital is required to perform the test. Costs for such a day case

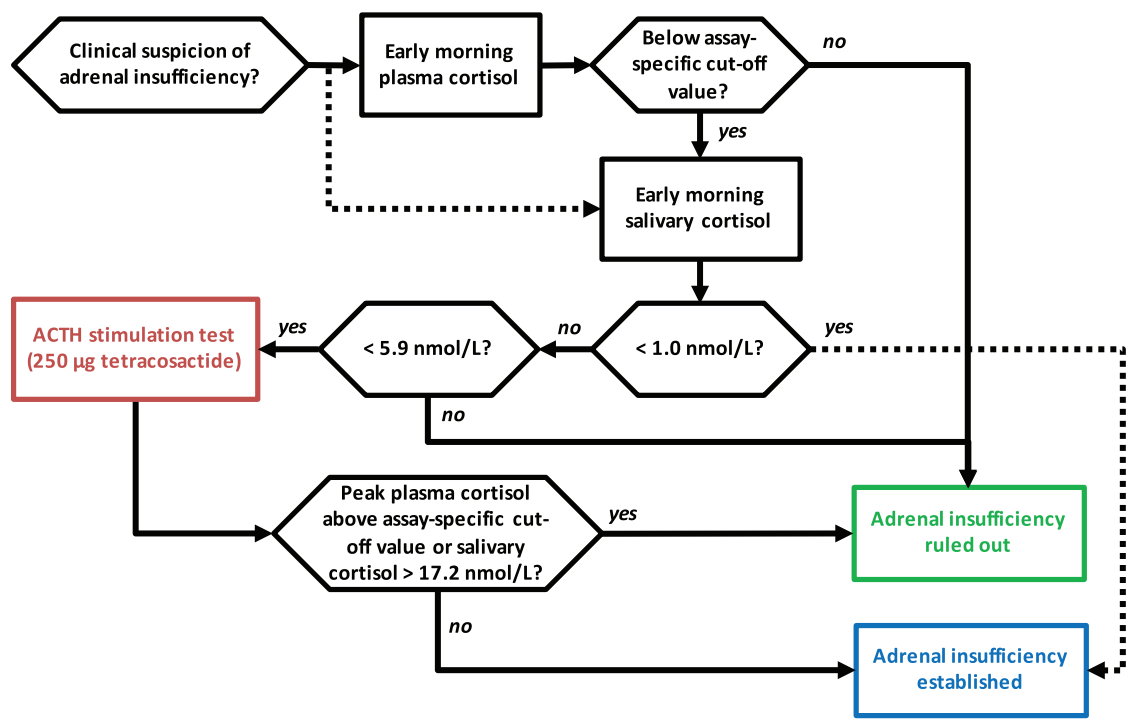

Figure 3

Novel diagnostic flowchart adrenal insufficiency. When a physician suspects $\mathrm{Al}$ in a given patient, an early morning plasma cortisol measurement will be performed. Concentrations above an assay-specific cut-off level (e.g. $550 \mathrm{nmol} / \mathrm{L}$ for cortisol I and $420 \mathrm{nmol} / \mathrm{L}$ for cortisol II) rule out Al. Below this cut-off level, a salivary cortisol measurement could be performed to select patients for an ACTH stimulation test. Early morning salivary cortisol concentrations $>5.9 \mathrm{nmol} / \mathrm{L}$ can rule out Al. Peak plasma or salivary cortisol concentrations after stimulation make up the diagnosis.

http://www.endocrineconnections.org https://doi.org/10.1530/EC-18-0085
() 2018 The authors Published by Bioscientifica Ltd
This work is licensed under a Creative Commons Attribution-NonCommercial-NoDerivatives 4.0 International License. 
admission are approximated to be several hundreds of euros per day per patient.

Current guidelines still advise an ACTH stimulation test in patients with morning plasma cortisol levels below $80 \mathrm{nmol} / \mathrm{L}$, although these concentrations are strongly predictive of AI (4). In our study, the minimum plasma cortisol concentration observed in normal subjects was $89.4 \mathrm{nmol} / \mathrm{L}$. A plasma cortisol below $80 \mathrm{nmol} / \mathrm{L}$ would thus also be strongly indicative of AI in our patient group.

Subnormal morning salivary cortisol levels have previously been investigated for the diagnosis of AI $(1,6$, $7,14,15)$. Sensitivity and specificity differed between the type of assay that was used to analyze salivary cortisol. Restituto et al. found a sensitivity and specificity of less than 35\%, based on salivary cortisol measurements by an ELISA (6). In addition, Marcus-Perlman et al. demonstrated that a single determination of basal salivary cortisol by modified RIA analysis was insufficient to separate hypoadrenal from normal subjects, considering the overlap between the groups (16). A more recent study using RIA analyses, however, found that a morning salivary cortisol value below $7.31 \mathrm{nmol} / \mathrm{L}$ distinguished patients with AI from controls with a sensitivity of $97 \%$ and specificity of 93\% (15). We demonstrated that LCMS/MS measurements of salivary cortisol increase the sensitivity and specificity, when adequate cut-off values are chosen. When mean salivary cortisol concentrations observed in patients without AI in our study (being $5.4 \pm 2.1 \mathrm{nmol} / \mathrm{L})$ are compared with values obtained by RIA $(12.1 \pm 1.6 \mathrm{nmol} / \mathrm{L}(16)$ or ELISA $(18.5 \pm 3.3) \mathrm{nmol} / \mathrm{L}$ (6)), lower concentrations are found by our LC-MS/MS method. As only cortisol is measured by LC-MS/MS, interaction with interfering substances is avoided. This might explain the observed differences between our study and others. The lower cut-off value that we defined for basal salivary cortisol (being $1.0 \mathrm{nmol} / \mathrm{L}$ ) is in line with results from Mak et al., who determined this cut-off value by defining the concentration with the highest area under the curve (AUC) in the ROC curve (14). With regard to performance of our LC-MS/MS method, the coefficient of variance around the cut-off value of $1 \mathrm{nmol} / \mathrm{L}$ is around $10 \%$, which is fairly acceptable for hormone assays.

In our study, reference values for early morning salivary cortisol and cortisone, as determined by the 97.5th percentile of normal (i.e. patients in whom AI was ruled out) were $1.6-34.4 \mathrm{nmol} / \mathrm{L}$ and $10.0-61.5 \mathrm{nmol} / \mathrm{L}$ respectively. These values are in line with other studies that determined salivary cortisol and cortisone concentrations by LC-MS/MS $(8,9,17)$. However, the upper limit of our reference interval for both salivary cortisol and cortisone is higher compared to these other studies. Differences in patient characteristics of the different studies may account for these differences. In addition, the cortisol awakening response in individuals and for example, actual timing of saliva collection after awakening will influence the observed reference values $(18,19)$.

After stimulation with tetracosactide, salivary cortisol reference intervals for $t=30 \mathrm{~min}$ and $t=60 \mathrm{~min}$ were $9.0-68.1 \mathrm{nmol} / \mathrm{L}$ and $12.6-123.4 \mathrm{nmol} / \mathrm{L}$ in our group of patients without AI. On the other hand, AI patients had salivary cortisol concentrations of $0.6-14.2 \mathrm{nmol} / \mathrm{L}$ and $0.5-15.2 \mathrm{nmol} / \mathrm{L}$ at $t=30$ and $60 \mathrm{~min}$ after stimulation respectively. Our upper limits of the reference intervals for all time points for both patient groups were higher compared to the results found by Perogamvros et al. (9). They investigated salivary cortisol concentrations after stimulation by tetracosactide and during insulin tolerance testing. A difference in definition of a normal response may explain differences observed in the AI patient group. However, Duskova et al. observed even lower values for the upper reference limit of salivary cortisol after stimulation by tetracosactide, as concluded from measurements in 15 healthy young men (17).

Measuring plasma cortisol concentrations during an ACTH stimulation test would still remain the gold standard in the Netherlands, as venous access is not a problem during day case submission and IV administration of tetracosactide. However, we demonstrated that the introduction of LC-MS/MS determined early morning salivary cortisol in the diagnostic work-up of suspected AI, could potentially reduce the numbers of ACTH stimulation tests. In addition, sampling of saliva is patient friendly. Promising future approaches in assessing adrenal function may include intramuscular injections of tetracosactide in a low dosage combined with salivary cortisol analyses, as investigated by Contreras et al. (20). This method may reduce the health care costs even further, as it can be performed in ambulatory patients. However, protocols for ACTH stimulation testing are still under debate (21). Assessing early morning salivary cortisol, as proposed in our diagnostic work-up, would be a first step to improve methods of assessing adrenal function and might lead to less ACTH stimulation test.

Declaration of interest

We have read and understood the policy on declaration of interests and declare that we have no competing interests. 


\section{Funding}

This research received no specific grant from any funding agency in the public, commercial, or not-for-profit sectors.

\section{Acknowledgements}

The authors would like to acknowledge laboratory technicians of the Catharina Hospital Clinical Laboratory for performing analyses of plasma cortisol and salivary cortisol and cortisone.

\section{References}

1 Raff H. Utility of salivary cortisol measurements in Cushing's syndrome and adrenal insufficiency. Journal of Clinical Endocrinology and Metabolism 200994 3647-3655. (https://doi.org/10.1210/ jc.2009-1166)

2 Inder WJ, Dimeski G \& Russell A. Measurement of salivary cortisol in 2012 - laboratory techniques and clinical indications. Clinical Endocrinology 201277 645-651. (https://doi.org/10.1111/j.13652265.2012.04508.x)

3 Bornstein SR, Allolio B, Arlt W, Barthel A, Don-Wauchope A, Hammer GD, Husebye ES, Merke DP, Murad MH, Stratakis CA, et al. Diagnosis and treatment of primary adrenal insufficiency: an Endocrine Society Clinical Practice Guideline. Journal of Clinical Endocrinology and Metabolism 2016101 364-389. (https://doi. org/10.1210/jc.2015-1710)

4 Bancos I, Hahner S, Tomlinson J \& Arlt W. Diagnosis and management of adrenal insufficiency. Lancet Diabetes and Endocrinology 20153 216-226. (https://doi.org/10.1016/S22138587(14)70142-1)

5 VigiBase. Uppsala, Sweden: Uppsala Monitoring Centre, 2016. (available at: http://www.who-umc.org/)

6 Restituto P, Galofre JC, Gil MJ, Mugueta C, Santos S, Monreal JI \& Varo N. Advantage of salivary cortisol measurements in the diagnosis of glucocorticoid related disorders. Clinical Biochemistry $2008 \mathbf{4 1}$ 688-692. (https://doi.org/10.1016/j.clinbiochem.2008.01.015)

7 Deutschbein T, Broecker-Preuss M, Flitsch J, Jaeger A, Althoff R, Walz MK, Mann K \& Petersenn S. Salivary cortisol as a diagnostic tool for Cushing's syndrome and adrenal insufficiency: improved screening by an automatic immunoassay. European Journal of Endocrinology 2012166 613-618. (https://doi.org/10.1530/EJE-110945)

8 Antonelli G, Ceccato F, Artusi C, Marinova M \& Plebani M. Salivary cortisol and cortisone by LC-MS/MS: validation, reference intervals and diagnostic accuracy in Cushing's syndrome. Clinica Chimica Acta 2015451 247-251. (https://doi.org/10.1016/j.cca.2015.10.004)

9 Perogamvros I, Owen LJ, Keevil BG, Brabant G \& Trainer PJ. Measurement of salivary cortisol with liquid chromatographytandem mass spectrometry in patients undergoing dynamic endocrine testing. Clinical Endocrinology 201072 17-21. (https://doi. org/10.1111/j.1365-2265.2009.03582.x)

10 El-Farhan N, Pickett A, Ducroq D, Bailey C, Mitchem K, Morgan N, Armston A, Jones L, Evans C \& Rees DA. Method-specific serum cortisol responses to the adrenocorticotrophin test: comparison of gas chromatography-mass spectrometry and five automated immunoassays. Clinical Endocrinology 201378 673-680. (https://doi. org/10.1111/cen.12039)

11 Kertai MD \& Fontes ML. Predicting adrenal insufficiency in severe sepsis: the role of plasma-free cortisol. Critical Care Medicine 201543 715-716. (https://doi.org/10.1097/CCM.0000000000000839)

12 Ho JT, Al-Musalhi H, Chapman MJ, Quach T, Thomas PD, Bagley CJ, Lewis JG \& Torpy DJ. Septic shock and sepsis: a comparison of total and free plasma cortisol levels. Journal of Clinical Endocrinology and Metabolism 200691 105-114. (https://doi.org/10.1210/jc.20050265)

13 Nederlandse Vereniging voor Laboratoriumgeneeskunde (NVKC). Wie doet wat database - cortisol in speeksel. Utrecht, the Netherlands: NVKC, 2018, (available at: http://www.nvkc.nl/ professional/wie-doet-wat-database?action=showdetail\&id=4290)

14 Mak IYF, Au Yeung BYT, Ng YW, Choi CH, Iu HYP, Shek CC \& Tiu SC. Salivary cortisol and cortisone after low-dose corticotropin stimulation in the diagnosis of adrenal insufficiency. Journal of the Endocrine Society 2017 96-108. (https://doi.org/10.1210/js.20161056)

15 Ceccato F, Barbot M, Zilio M, Ferasin S, Occhi G, Daniele A, Mazzocut S, Iacobone M, Betterle C, Mantero F, et al. Performance of salivary cortisol in the diagnosis of Cushing's syndrome, adrenal incidentaloma, and adrenal insufficiency. European Journal of Endocrinology 2013169 31-36. (https://doi.org/10.1530/EJE-13-0159)

16 Marcus-Perlman Y, Tordjman K, Greenman Y, Limor R, Shenkerman G, Osher E \& Stern N. Low-dose ACTH (1 microg) salivary test: a potential alternative to the classical blood test. Clinical Endocrinology 200664 215-218. (https://doi.org/10.1111/j.13652265.2006.02451.x)

17 Duskova M, Simunkova K, Vitku J, Sosvorova L, Jandikova H, Pospisilova H, Šrámková M, Kosák M, Kršek M, Hána V, et al. A comparison of salivary steroid levels during diagnostic tests for adrenal insufficiency. Prague Medical Report 2016117 18-33. (https:// doi.org/10.14712/23362936.2016.2)

18 Clow A, Hucklebridge F, Stalder T, Evans P \& Thorn L. The cortisol awakening response: more than a measure of HPA axis function. Neuroscience and Biobehavioral Reviews 201035 97-103. (https://doi. org/10.1016/j.neubiorev.2009.12.011)

19 Stalder T, Kirschbaum C, Kudielka BM, Adam EK, Pruessner JC, Wust S, Dockray S, Smyth N, Evans P, Hellhammer DH, et al. Assessment of the cortisol awakening response: expert consensus guidelines. Psychoneuroendocrinology 201663 414-432. (https://doi. org/10.1016/j.psyneuen.2015.10.010)

20 Contreras LN, Arregger AL, Persi GG, Gonzalez NS \& Cardoso EM. A new less-invasive and more informative low-dose ACTH test: salivary steroids in response to intramuscular corticotrophin. Clinical Endocrinology 200461 675-682. (https://doi.org/10.1111/j.13652265.2004.02144.x)

21 Kosak M, Duskova M, Starka L, Jandikova H, Pospisilova H, Sramkova M, Hana V, Krsek M, Springer D \& Simunkova K. Can the gold standard be beaten? How reliable are various modifications of the Synacthen test compared to the insulin tolerance test. Physiological Research 201766 S387-S395. (available at: http://www. biomed.cas.cz/physiolres/pdf/66/66_S387.pdf)

Received in final form 27 February 2018

Accepted 12 March 2018

Accepted Preprint published online 12 March 2018 http://www.endocrineconnections.org https://doi.org/10.1530/EC-18-0085
() 2018 The authors Published by Bioscientifica Ltd
This work is licensed under a Creative Commons Attribution-NonCommercial-NoDerivatives 4.0 International License. 